\title{
Study on Blended Learning Model for College English Teaching Based on Moodle System
}

\author{
Liu Xiaqing ${ }^{1, a^{*}}$, Li Songqing ${ }^{1, b}$ and Dun Xiaohui ${ }^{1, c}$ \\ ${ }^{1}$ Shandong Technology and Business University, Yantai, Shandong, China 264000 \\ aliuxiaqing111@163.com, ${ }^{b} 332853225 @ q q . c o m,{ }^{c} 578412118 @$ @q.com
}

Keywords: Blended learning; College English teaching; Teaching model; Moodle system

\begin{abstract}
With the development of college English education and improvement of modern education technology, blended college English teaching model has become a development direction for college English teaching reform. Blended teaching combines e-learning and face-to-face classroom teaching, aiming to promote learners' autonomous learning, and cultivate their ability of discovering, analyzing, and solving problems. On the basis of introducing blended learning concepts and teaching platform shareware Moodle, this paper, focusing on the construction of college English blended teaching model, explores the basic process and key factors for the blended college English teaching based on Moodle teaching platform.
\end{abstract}

\section{Introduction}

"College English Curriculum Requirements" which was issued by Ministry of Education in 2007 confirms the teaching objective for college English teaching that cultivate comprehensive proficiency in applying English, especially for listening and speaking ability. Unlike first language learning, a lot of time and energy should be needed for second language learning. However, most of universities and colleges are reducing amount of class time, from 8 class hours per week to four class hours per week, which result in the fact that it is more difficult for learners to achieve the requirement of listening and understanding academic literatures only by means of face to face teaching. For instance, "College English Curriculum Requirements" requires that the average reading speed for college students is 70 words per minute and 100 words per minute for fast reading. The assessment reading gauges for non-English major learners of other languages made by linguists are 60 words per minute - very slow, 80 words per minute - slow, 120 words per minute - ordinary, 150 words per minute — fast, and 180 words per minute - very fast. It can be clearly known that English reading ability of Chinese learners is far slower.

In this case, instruction assisted by modern technology shows its advantages, for it can enrich the input of instruction activities, promote vocabulary and writing learning, provide authentic material for learners, and finally increase language learning interests. Therefore, the reform direction for college English teaching should direct to resource sharing, IM (instant messaging), and individualized and autonomous learning.

However, one of key problems for language blended teaching is how to construct an effective network teaching management platform, which can arrange learning resources, control and lead learning activities, and analyze learners' performance. At present, popular network learning management platforms include WebCT, Blackboard, Moodle, SPOC, Sakai, Bodinton, Atutor, and so on. Moodle, as an open source system, draws more and more attention and have accepted wide recognition and recommendation. Therefore, this paper focus on blended college English teaching reform based on Moodle system.

\section{Literature Review}

Blended Learning. Blended learning or blending learning was put forward by foreign scholars. As early as in 2002, NIIT, an Indian company, in its "Blended Learning White Paper", defined blended 
leaning as a kind of leaning method, which covers face-to-face learning, real time e-learning, and user-defined learning. In most cases, blended learning is elaborated as mixed application of multiple technologies, such as media for information delivery, intelligent learning, e-learning, electronic performance evaluation, and learning resource management. Blended learning is defined as a learning ability as well, which require that learners choose their favorite facility, instrument, technology, and media by themselves, teachers organize and implement instruction by means of equipment, instruments, technology, media, and teaching material, and managers have management and allocation competence.

In China, blended learning was described as combination of advantages of traditional class teaching and digital teaching. [1] Professor Li proposed that it would be useful to adopt different media and information transmission methods according to specific problems in learning activities. [2]

The essence of blended learning is to combine e-learning and traditional learning. The former refers to teaching and studying by means of internet, which can provide a brand new and rich learning environment. [3] Traditional learning takes language and textbook as media, and teachers' instruction and class learning as learning pattern. Blended learning aims to satisfy students' need and maximize learning effect.

Moodle System. Moodle system is one of the most popular course management systems (CMS). Moodle is short for Modular Object-oriented Dynamic Learning Environment, which was developed by Dr. Martin Dougiamas in Australia based on constructivism educational theory. The system can be used as a management platform for online course, and an extension for traditional class teaching. Constructivism holds the idea that knowledge is acquired by means of interaction between learners and between learners and environment through kinds of learning resources and learning methods. Moodle pays attention to content of courses and teaching activity diversification, which invoke deep thinking about the roles of learners, teachers and managers.

Moodle is constructed based on modules, by which users can adjust learning interface and modify teaching contents in accordance with learning style and learners' capacity. Various functions of online teaching platform can be realized on the Moodle system, including course management, learning record trail, grouping, and course resource management, assessment, testing, and online teaching. Besides, there are a lot of interactive modules on Moodle, such as wiki, discussion board, and on-line answer. In the view of its powerful capability, sometimes it is even regarded as a replacement learner platform for Blackboard.

There are different roles in Moodle system, each of which has its own authorities. Three fixed roles are administrator, teacher and learner respectively. Administrator with the highest management and edit authority can conduct system layout and manage courses and users. Course management includes course establishment, course type setting-up, and teacher management. User management refers to setting-up of logon pattern, account and authority. System layout covers site home page and operation interface designing, configuration parameter, and plug-in setting-up.

Teachers are responsible for instruction preparation, designing, implementation and assessment. Instruction preparation refers to publish and design courses, learning material lead-in, and making PPT. Instruction designing includes formulating and determining teaching plan, teaching objectives or outcome, teaching syllabus, assessment criteria, and corresponding teaching strategies and methods. Instruction implementation refers to parameter setting for learning activities.

Learners, subjects of Moodle learning, answer for pre-class preparation, course learning and assessment. Pre-class preparation refers to enrollment and browsing learning plan, syllabus, course introduction, and announcement. Course learning covers reading material, watching and downloading PPT and relevant resources, discussing in forum, and practicing and exercises. Assessment means learning experience accumulation and summary. 


\section{College English Blended Teaching Model Construction}

Some key issues should be straightened out as regards college English blended teaching model construction. [4] The first and foremost thing is to understand the essence of college English teaching model based on the online and off-line instruction is an autonomous learning model led by teachers. The model construction aims at promoting the formulation of customized leaning and improve the learners' autonomous learning ability.

Firstly, a well-improved learning environment is needed for the model construction. In the blended teaching model, customized or individualized teaching and autonomous learning are emphasized. Learners choose teaching contents and learning methods best fitful for themselves according to their characters, learning levels, interests, and times, as so to maximize the learning effect. For example, some learners can read news and journals silently, and others can take part in the forums discussions. No matter what kind of learning forms the learners choose, they can immerse in a more authentic language learning environment.

Secondly, college English blended teaching model can take advantage of dynamic and diversity of online communication. Learners can interact with each other through online teaching platform. They can express themselves by the means of videos, animation, sounds, and pictures. The blended teaching model can provide performance assessment to users. As for teachers, they can adjust the teaching pace, material, presentation sequence according to the feedback. Learners can know well about their learning status of their peers'. In this way, they can know the gap between them, which will motivate their learning autonomy.

Thirdly, college English blended teaching model can enhance autonomous learning ability. There are numerous learning resources on the platform. The model can provide self-monitoring methods by uploading learning requirement, assignment, key points explanation, references, and so on. Actually, teachers can upload different teaching materials and resources in consideration of their learning level, study schedule, and acceptance.

Finally, the college English blended teaching model can optimize teaching assessment model by combing formative evaluation and summative evaluation. The online platform can provide formative evaluation which can take proportion in final assessment, for example, 50\% or even more. In that case, learners' engagement time, number and quality of messages posted online can contribute to the final assessment. With the development of the modern education technology, question bank and test online can be used for final examination, which can save a lot of time and energy.

\section{College English Blended Teaching Model Based on Moodle}

There are mainly five factors for Moodle-supported college English blended teaching model, namely, learning environment construction, course designing and development, class face-to-face instruction, online instruction, and blended teaching assessment. [5] It can be shown in the following Fig.1.

Constructive Learning Environment Design. Constructive learning environment consists of two parts, hard environment and soft environment, or entity environment and online environment. Entity environment refers to the hardware equipment, computer facilities, internet access, hubs, and so on. Online environment includes teaching environment, learning environment, and management environment. The two environments are connected with each other by means of internet and intranet. Most of universities and colleges are equipped with computer rooms, laboratories, and complete coverage of network. In this case, Moodle system can set up smoothly. 


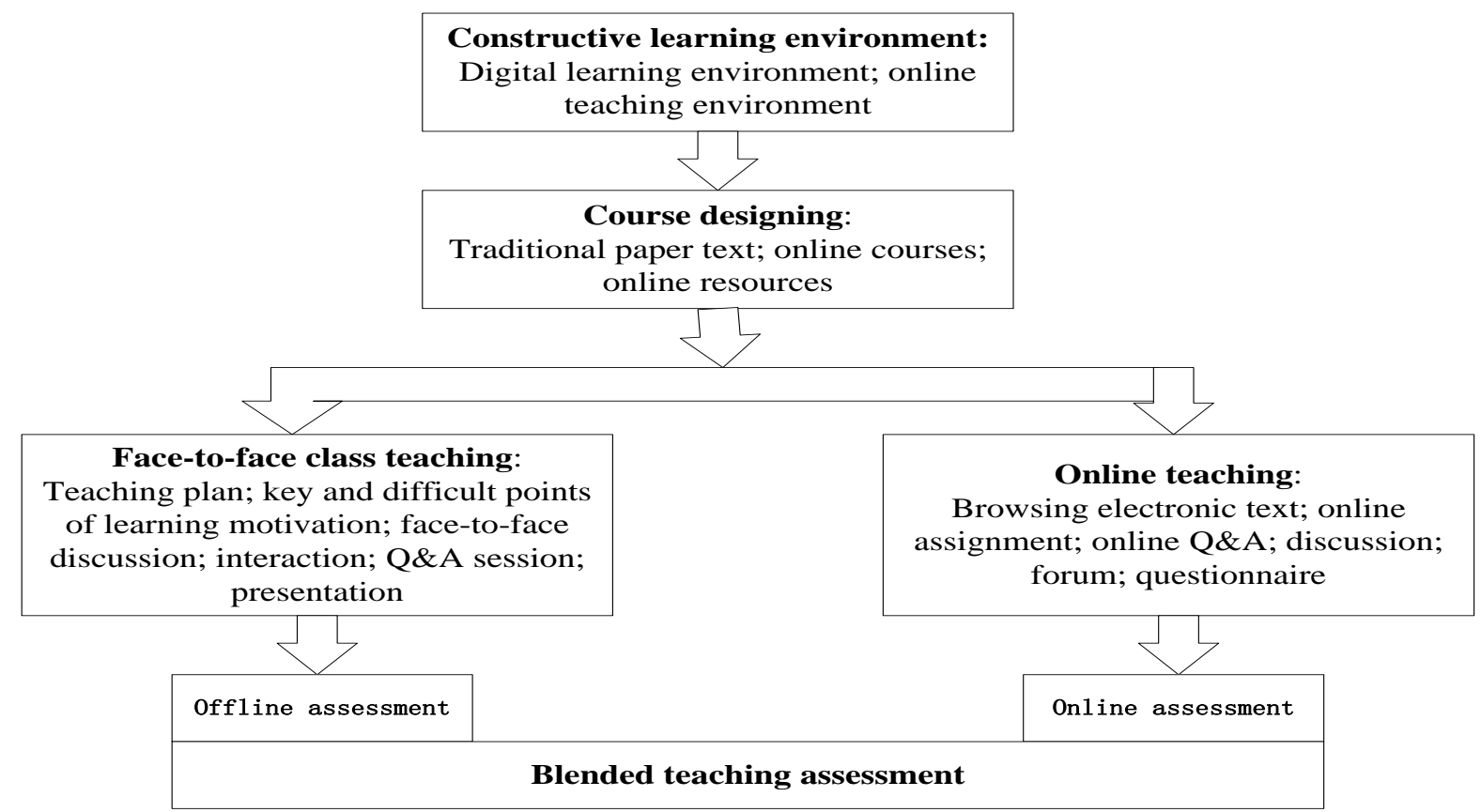

Figure 1. Moodle-based college English blended teaching model flowchart

Course Designing and Development. It is the first step for platform and system setting up. Course contents are the carrier of information transmission, which should be well organized and designed. The course contents are composed of textbook, corresponding exercises and online resources. For example, many universities and colleges adopt "New Horizon College English" as textbooks for non-English major students which were published by Foreign Language Teaching and Research Press. The textbook materials can help student preview, review, and complete assignments. The series of books is characterized as rich content and complete ancillary. Its New Horizon English Listening \& Speaking is full of multimedia video and listening materials, through which learners can do autonomy learning anytime and anywhere as they like. The interface can be illustrated in Fig. 2 . Users can publish assignments in the form of off-line file or on-demand submits. If there is something wrong, users may resubmit the file and the new one will replace the former one automatically. After the submission, the user can read the similarity with papers or assignments from the same system, which can help learns submit the original work instead of scrapping from the internet. Learners can give feedback to the tutor and submit study feedback report which will be helpful for English learners for they can form the habit of regular writing. The main body part of the interface is course contents. Teachers publish the contents of each week on the board. The forum part provides peer review function, and they can also air their opinions about the course or interesting related topic.

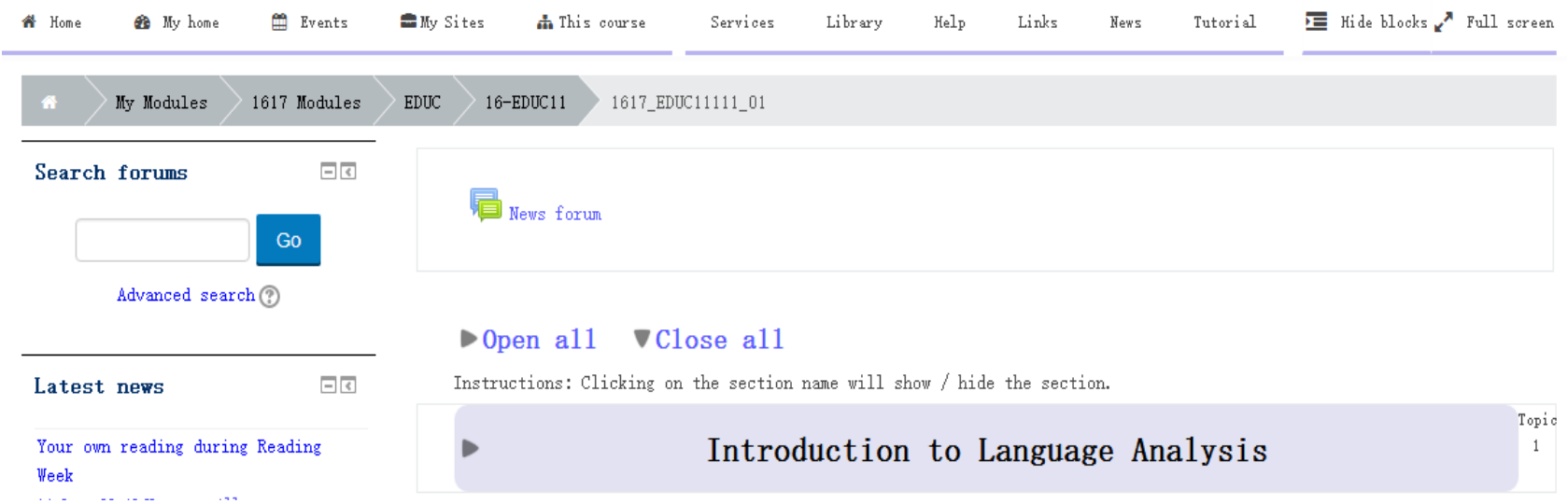

Figure 2. Screen shot of Moodle interface

Face to Face Class Teaching. No matter how popular the online teaching becomes, face-to-face class teaching is necessary and essential especially for language teaching. In the blended teaching 
class, learners should be trained to know how to use online teaching and learning system, where to find the teaching plan, activity arrangement, and course assessment details. Maybe some of the learners are reluctant to accept the blended teaching, so show the benefits to them. For example, the face-to-face class teaching will be more effective if the minor or basic issues are solved online. Make sure important and difficult points should be emphasized in face-to-face class teaching. Team collaborative work is recommended in the face-to-face class teaching. Most of the procedures can be conducted online except for achievement presentation, which will be in favor of peer view, deep discussion, and overcome problems.

Online Teaching and Learning. Limited by class instruction time, a lot of works are left for self-study. Frequently used teaching activities include the following: writing study note after reading or browsing some online course; collaborative and task-based learning by means of forum function; intensive training for some important and difficult points; Q\&A in chatting room.

Blended Teaching Assessment. Blended teaching assessment includes traditional teaching assessment mainly in forms of paper and online teaching assessment. Teachers can check electronic records of each student and give them feedback by means of face-to-face communication, e-mail, forum and message, which on one hand can motive students' language learning; on the other hand, can keep records of their progress and hardworking. For example, although a student gets a so-so grade in the final examination, but we can see his or her progress and hardworking from the electronic records, then maybe he or she deserves a big $\mathrm{A}$ in the final assessment report.

\section{Summary}

Traditional face-to-face class teaching has such disadvantages of single form, limited interaction, and rigid assessment, while online teaching can make up for those disadvantages by means of online courses, extended teaching materials and various online interactive activities. Blended teaching is not a brand new teaching or learning concept and method, and it draws highlights with the deepening of education informationizaiton. It combines face-to-face class teaching and online teaching together, which provides a feasible and scientific method for college English reform. Furthermore, it can exert teachers' leading role and give play to learns' autonomy. Moodle system, characterized as zero cost, usability, expandability, and flexibility, provides an effective platform for college English blended teaching.

\section{Acknowledgements}

This paper is sponsored by Teaching Reform Project of Shandong Technology and Business University (No. 11688JXYJ2015009).

\section{References}

[1] S. S. Tian, G. S. Fu, Preliminary study on blended learning, E-education Research. 7 (2004) 51-59.

[2] K. H. He, on the new development of education technology theory from the perspective of blending learning, Journal of Beijing Normal University, 3 (2004) 5-10.

[3] K. D. Li, J. H. Zhao, Principle and application model of blended learning, E-education Research.7 (2004)1-6.

[4] Y. Zhang, J. Gao, Application of college English blended teaching model, Chinese Journal of ICT in Education. 9 (2015) 55-59.

[5] S. J. Chen, W. Q. Ma. Study blended teaching model based on Moodle, Journal of Qujing Normal University. 11 (2007) 55-60. 